\title{
"Coisas Engraçadas": análise de interações no contexto de construção de uma narrativa em uma escola de Educação Infantil
}

\section{"Fun Stuff": analysis of the interactions in the context of the narrative building process at an early childhood education school}

André Luiz Pancotto é professor formador na rede municipal de educação de Caieiras (SP), especialista em Gestão Pedagógica e Formação na Educação Infantil pelo Instituto Vera Cruz.

\section{Contato: andre.pancotto@gmail.com}

Marisa Vasconcelos Ferreira é psicóloga e doutora em Educação: Currículo. Docente do curso de Especialização em Gestão Pedagógica e Formação na Educação Infantil, da Graduação em Pedagogía e coordenadora do Núcleo de Pesquisas em Educação Infantil, no Instituto Vera Cruz.

Contato: marisavferreira@gmail.com.

\section{Resumo}

Este trabalho visa contribuir com as reflexões sobre as práticas pedagógicas que envolvem as linguagens oral e escrita nos contextos de Educação Infantil. Para tanto, analisa interações das crianças na construção de uma narrativa escrita coletiva, tendo como recurso a leitura de um livro de imagens. $\mathrm{Na}$ análise, enfatizou-se o olhar para as interações e como estas foram constituindo as soluções do grupo para a narrativa. Foram definidos como eixos de análise aspectos relativos ao pensamento, à fala e ao letramento emergente, além dos gestos que contribuíram com a constituição da situação interativa. Por fim, reflete-se sobre a importância de constituir práticas pedagógicas envolvendo as diferentes linguagens na Educação Infantil, articuladamente e inseridas nas práticas sociais.

Palavras-chave: Interação social. Linguagem verbal.

Educação Infantil. Letramento. 


\begin{abstract}
This work aims to contribute to the reflections about pedagogical practices involving oral and written languages in the contexts of Early Childhood Education. Therefore, analyse the interactions of children during the construction of a collective narrative, having as a resource: reading a picture book. The look for interactions was emphasized and how they constitute group's solutions for the narrative. So, they were defined as axes analysis, aspects of syncretic thought, speech literate and emerging literacy, in addition to gestures that contributed to creating the interactive situation. At sum, it is reflected on the importance of forming pedagogical practices involving different languages in Early Childhood Education, integrated and contextualized social practices. Keywords: Social interaction. Verbal Language. Gesture. Early Childhood Education. Literacy.
\end{abstract}

\title{
Introdução
}

0 presente artigo analisa episódios de interação acontecidos em uma turma de crianças e sua professora, no contexto de construção coletiva de uma narrativa escrita, em uma escola de Educação Infantil. Busca-se refletir sobre práticas pedagógicas que envolvem as linguagens oral e escrita no contexto da Educação Infantil, buscando ampliar o olhar para as interações das crianças no contexto dessas situações e as possibilidades de aprendizagem que se colocam.

Convergem aqui diferentes temáticas, a saber, as interações das crianças com seus pares e com a professora, assim como as linguagens oral, escrita e gestual, que se mostram importantes e desafiantes aspectos na construção de propostas pedagógicas adequadas às especificidades das crianças em seus anos iniciais de escolaridade.

Assumimos aqui a compreensão de currículo definida nas atuais Diretrizes Curriculares Nacionais para a Educação Infantil, que destacam uma preocupação com a articulação das experiências e saberes das crianças com os conhecimentos que compõem o patrimônio cultural, artístico, ambiental, científico e tecnológico do contexto sociocultural em que estamos imersos (Brasil, 2009a). 
Assim, na organização das propostas curriculares, as linguagens oral e escrita constituem práticas socialmente construídas nessa história cultural e saberes de fundamental importância para o desenvolvimento integral das crianças em seus anos iniciais de vida. Concordamos com Baptista (2010) que:

\begin{abstract}
(...) o trabalho com a linguagem escrita na educação infantil se justifica por considerarmos que a criança produz cultura e que essa produção se realiza na interação que ela estabelece com o mundo e com as diversas produções culturais desse mundo. A escrita é um elemento importante dessa cultura com a qual a criança interage e demonstra interesse em compreendê-lo e dele se apropriar (BAPTISTA, 2010, p.4).
\end{abstract}

Refletir sobre essas aprendizagens a partir da ideia de prática social nos ajuda a superar fragmentações e propostas descontextualizadas, sem sentido e entediantes para as crianças, bem como distantes das funções comunicativas necessárias para a imersão no universo das práticas sociais de leitura e escrita. Essas práticas, que teimam em permanecer não apenas nas instituições de Educação Infantil, mas também em propostas curriculares de redes de ensino e projetos de políticas públicas, pautam-se nas repetições de fonemas e cópias de letras, sílabas ou palavras, falsamente sustentadas no argumento de que é preciso iniciar o quanto antes o processo de alfabetização.

Nessa direção, vale ressaltar com Luize (2016) que o trabalho com a língua escrita na Educação Infantil não tem como meta que as crianças concluam essa etapa da educação apresentando uma escrita convencional. 0 que se espera é promover:

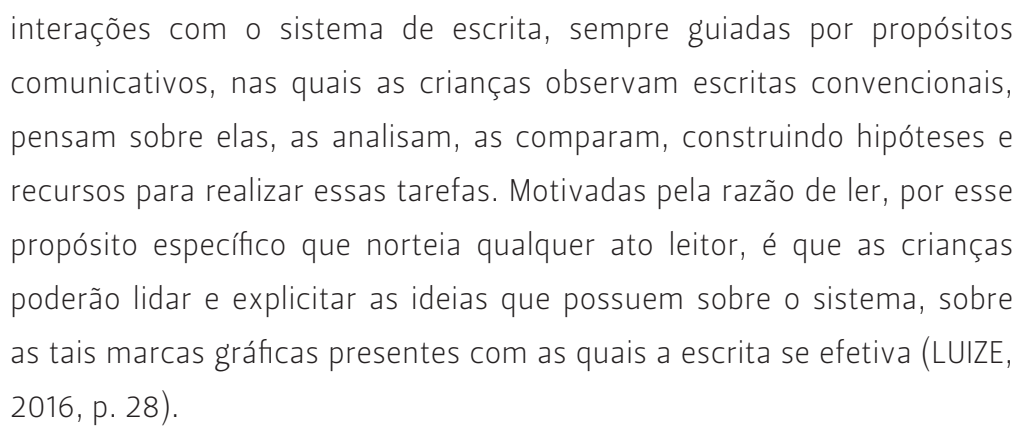

A partir do momento em que as práticas sociais, os propósitos comunicativos reais, passam a pautar o trabalho com a escrita no contexto da Educação Infantil, a valorização da atividade criadora da criança, na interação com seu meio social, ajuda a promover espaços em que situações de uso social favorecem as aprendizagens em práticas conectadas à vida cotidiana. 
Foi com esse olhar que buscamos aprofundar a reflexão sobre as interações que se desenrolaram entre as crianças e destas com a professora, em uma atividade de construção de uma narrativa escrita construída coletivamente, pautada pela mediação da linguagem oral. Trazemos aqui alguns apontamentos a fim de compreender processos interacionais, de aprendizagem e de construção da linguagem que se concretizaram nessa situação.

\section{Aspectos acerca da construção da linguagem nos anos iniciais da infância}

Buscamos no referencial sócio histórico do desenvolvimento humano alguns aspectos que nos ajudaram a olhar para as interações das crianças mediadas pela proposta de construção de uma narrativa coletiva.

Entendemos que ao nascer, o bebê humano é caracterizado por uma incompletude motora que o coloca em uma situação de extrema dependência em relação a outro ser humano. Wallon (1975) aponta essa relação necessária à sobrevivência humana e, ao mesmo tempo, caracteriza a base do desenvolvimento humano, a interação eu-outro.

O bebê humano precisa do outro como seu parceiro em uma relação que vai mediar o seu contato com o mundo e com os objetos. 0 eu, desde o início, vai sendo constituído na interação com o outro, e aqui destacamos o lugar da linguagem como meio primordial a promover a inserção desse bebê na cultura.

Ao buscar nos estudos linguísticos as relações entre a construção da linguagem verbal e os primórdios do desenvolvimento humano, destacamos com Rojo (2010) o entendimento de que o processo pelo qual a criança constitui pouco a pouco o letramento tem a sua gênese na oralidade, que se inicia com as falas maternas, quando a mãe e os outros com quem o bebê interage, ao nomear objetos, sentimentos, sensações e ações, significam o mundo aos bebês.

Esse bebê, ao contrário do que se pensava, é um parceiro ativo nessa interação. Concordando com Wallon (1975), entendemos que essa atividade (que não quer dizer intencionalidade) se faz por meio dos seus movimentos e gestos que, pouco a pouco vão sendo significados por essa criança. "Os primeiros gestos que são úteis à criança não são gestos que lhe permitirão apropriar-se 
dos objetos do mundo exterior ou evitá-los; são gestos para as pessoas, são gestos de expressão" (WALLON, 1975, p. 205).

A partir das falas iniciais dos seus parceiros de interação no início da vida, a criança inicia o processo de atribuição de significados por meio da linguagem, processo esse que vai se aperfeiçoando com as interações e jogos linguísticos, como o "Cadê? Achou!!", e os jogos de nomear objetos, pessoas, partes do corpo, bem como, mais à frente, nas interações dos adultos com as crianças nos momentos em que conversam sobre o que fizeram durante o dia ou antecipam o que será feito etc.

Nesse processo, é fundamental a diversidade de tipos de narração promovidos nas e pelas interações com os pequenos, como as leituras de histórias, e aqui a instituição de Educação Infantil se coloca como meio privilegiado para enriquecer o repertório infantil. Assim, rodas de histórias, rodas de conversar, músicas e as diversas possibilidades de jogos (de papéis, de nomear, de contar) são bons promotores de desenvolvimento da linguagem.

Ressalte-se, ainda, que numa instituição de Educação Infantil há inúmeros momentos de interação mediados pela linguagem que oferecem elementos discursivos importantes para as crianças, e grande parte dessas situações ocorrem durante/através das conversas estabelecidas entre as próprias crianças enquanto brincam, desenham, constroem, jogam etc.

É preciso retomar ideias que historicamente explicaram o desenvolvimento da linguagem verbal e sustentaram práticas educativas. Durante muito tempo se compreendeu o processo de desenvolvimento da linguagem de forma linear, cumulativa e segmentada. Isto é, primeiro a criança aprendia a falar (modalidade oral da linguagem) e, só depois, a escrever. Essa é uma compreensão que ordena a aquisição das linguagens oral e escrita em etapas diferentes e consecutivas. Além disso, uma tradição associacionista na compreensão acerca da linguagem compreendia fala e escrita de forma isomórfica e, dessa maneira, se a criança falante aprendesse as correspondências fonografêmicas, ela escreveria (ROJO, 2010).

Talvez decorram dessas referências algumas concepções sobre a fala e escrita, presentes no debate da Educação Infantil, que veem na primeira linguagem, a da oralidade, uma certa naturalidade no desenvolvimento da criança, enquanto a segunda, a linguagem escrita, encerraria posicionamentos extremos e 
reducionistas. De um lado, os que buscam afastar as crianças de situações que promovem experiências com a linguagem escrita, porque supostamente isso englobaria aprendizagens que não deveriam acontecer nos primeiros anos de vida. De outro, os que compartilham uma concepção mecanicista de alfabetização, reeditando na Educação Infantil práticas de ensino que focam a repetição e cópia de letras, sílabas e memorização do abecedário'.

Seja excluindo a escrita - saber próprio de uma cultura letrada e notoriamente foco de interesse das crianças - seja a considerando algo descontextualizado, sem vinculação com a vida real, com as práticas culturais que a significam, ambas as concepções segmentam fala e escrita, colocando-as em processos distintos e lineares, perdendo de vista a integralidade do desenvolvimento e a especificidade da infância, que é interagir criativamente com os elementos da cultura, nesse caso as diferentes linguagens, e colocar em jogo essas diferentes aprendizagens.

Essas ideias já vêm sendo questionadas pelos estudos desenvolvidos no campo da psicolinguística, dentre os quais aqueles decorrentes de uma perspectiva sócio-histórica. Se compreendemos o desenvolvimento da criança a partir de uma perspectiva cultural, portanto do sujeito em interação social, devemos ressaltar que, por meio desse outro, parceiro de interação, a criança é inserida no mundo da linguagem com todas as suas modalidades.

Como Rojo (2010), compreendemos a superação de um olhar que foca apenas a compreensão da oralidade e escrita em suas propriedades formais para entender a construção da linguagem como engendramento do sujeito em sua cultura.

\section{(...) se interrogarmos a linguagem não mais nas manifestações de sua materialidade pura, mas como processo constitutivo de sujeitos, em sua subjetivação e em sua objetivação e, logo, de atos desse sujeito sócio- historicamente situado; veremos que várias mudanças operam-se também em nossas concepções, sobretudo no que se refere às relações entre oralidade/escrita no processo de letramento e a seu modo de constituição (ROJO, 2010, p. 57).}

A oralidade passa, assim, a subsumir não só processos de fala, mas também da linguagem escrita, pois, no uso social, uma fala inicial pode se transformar em outro tipo de fala que incorpora elementos da própria escrita, fazendo emergir na interação o que se convencionou chamar de fala letrada.
1. Vale comentar que, muitas vezes, as críticas a essa concepção vêm acompanhadas de falas que relacionam essas práticas de trabalho com a linguagem escrita a práticas próprias do Ensino Fundamental. Aproveitamos para afirmar que, mesmo quando se inicia um processo mais sistemático de alfabetização - próprio do Ensino Fundamental -, essas práticas reducionistas e descontextualizadas não se mostram adequadas. Sem adentrar nesse amplo debate, importa afirmar que esse tipo de trabalho, que não queremos para as crianças da Educação Infantil, também não responde às necessidades de aprendizagem das crianças no Ensino Fundamental. 
A fala letrada e a emergência do processo de letramento, de acordo com Rojo (2010), se constroem a partir do contato e utilização da linguagem na qual a criança está imersa desde o nascimento. As situações sociais de uso da linguagem oral vivenciadas pela criança - ainda que, por vezes, apenas como ouvinte/expectadora - são internalizadas e resgatadas nos momentos de elaborações discursivas próprias. Internalização aqui usado no sentido vigotskiano de reconstrução interna de algo que, inicialmente, era externo; portanto, que supõe apropriação e ressignificação pelo sujeito.

Na medida em que a criança apropria-se dos recursos narrativos que constituem as situações orais - ressalte-se: porque alguém usou antes dela -, pode-se afirmar que sua fala se transforma, paulatinamente, em uma fala letrada, posto que passa a empregar, em suas construções linguísticas, vocábulos e conectivos cada vez mais complexos, tornando sua fala mais conexa e completa, se pensamos no processo comunicativo.

É importante salientar que esse não é um processo cumulativo, evolutivo, no sentido linear de desenvolvimento. 0 processo de construção da linguagem se faz com idas e vindas, demanda reorganizações e uma complexidade que não se explica se pensarmos apenas em uma lógica de acúmulo e ganhos. Essa compreensão relaciona-se à compreensão apresentada por Marcuschi (2001) sobre o uso da língua dando-se em um "... continuum de relações entre modalidades, gêneros textuais e contextos socioculturais" (MARCUSCHI, 2001, pp. 23-24). Nessa direção, entende-se o conceito de letramento como prática social situada, isto é, como os usos culturais de textos escritos em contextos sociais (MARCUSCHI, 2001).

Essa forma de compreender o letramento está relacionada à noção de fala letrada, entendendo que sua construção por parte dos sujeitos, inseridos em determinado contexto social, supõe a participação ativa nas situações reais de fala, leitura e escrita.

Destaca-se, então, que o processo de construção da linguagem depende, portanto, das oportunidades de envolvimento efetivo das crianças com as linguagens oral e escrita (em seus diferentes usos). Assim, crianças imersas num ambiente letrado, com adultos e outras crianças fazendo uso efetivo dos recursos linguísticos e narrativos em práticas sociais de uso da linguagem, apresentam maiores recursos nesse processo de construção (ROJO, 2010).

Nessa vertente, a autora ressalta a relação de dependência existente entre oralidade e escrita no processo de letramento. 
A dependência entre elas se configura pelo fato de que, em inúmeras situações, a fala é decorrente da linguagem escrita, como é o caso da leitura em voz alta de histórias, de modo a significar a leitura como uma situação de oralização do texto escrito. Desse modo, a criança entra em contato com formas diferentes de escrita (por exemplo, por meio dos gêneros literários diversos), o que contribui com a ampliação de suas formas de dizer.

Olhando essa relação de dependência às práticas de oralidade, jogos de contar ${ }^{2}$ também potencializam o processo de desenvolvimento da fala letrada, uma vez que a criança, ao contar histórias e casos, emprega recursos característicos da linguagem escrita, podendo utilizar, dentre outros elementos, conectivos e vocábulos expressos nos textos/histórias que Ihe foram lidos e/ou contados em situações anteriores.

A própria entonação e a alteração de voz durante o ato de contar histórias podem advir de marcas linguísticas presentes na linguagem escrita, que são contextualizadas/(re)significadas para as crianças nos momentos de leitura de histórias, como as pontuações, rimas, construções estilísticas, vocábulos, dentre outras possibilidades de recursos oferecidos pela linguagem escrita.

Assim, esse processo de letramento concretiza-se pela apropriação e uso dos recursos disponíveis na linguagem falada e na escrita. Ainda mais, é considerado emergente, por se tratar de todo o processo inicial e crescente de interiorização e apropriação da escrita.

Nesse momento, gostaríamos de retomar aqui a questão do movimento e do gesto no processo de construção da linguagem pela criança. Como havíamos já indicado, o gesto está presente desde o início da vida e vai ganhando significado à medida que o bebê se desenvolve em suas diferentes linguagens. Portanto, se oralidade e escrita vão de diferentes formas se imbricando, também a linguagem gestual entra nessa interação, compondo mais uma das dimensões humanas de desenvolvimento.

Portanto, na compreensão dos significados e sentidos construídos pelas crianças, nas e por meio das interações que estabelecem, essa multiplicidade de linguagens entra em jogo - oralidade, gesto e escrita - constituindo e ressignificando os elementos da cultura no aqui e agora das situações. Essa é a riqueza da criatividade das crianças.

Sendo assim, se compreendemos que, desde os momentos iniciais da vida, a criança está imersa em um contexto de uso das 
diferentes linguagens que se constituem como práticas de uso social, então, a questão (que, aliás, não é nova para a escola, já que se refere ao eterno dilema da constituição dos conteúdos escolares) diz respeito a como promover nas práticas pedagógicas da Educação Infantil condições de trabalho didático que assumam as linguagens oral e escrita como práticas de uso social, assim como o gesto como linguagem fundamental na construção do pensamento e fala das crianças. Ressaltando a ideia de que a escrita deve ser "relevante à vida", Vigotski afirma:

\begin{abstract}
(...) o melhor método é aquele em que as crianças não aprendam a ler e a escrever, mas sim descubram essas habilidades durante as situações de brincadeira. Para isso é necessário que as letras se tornem elementos da vida das crianças, da mesma maneira como, por exemplo, a fala. Da mesma forma que as crianças aprendem a falar, elas podem muito bem aprender a ler e a escrever. Métodos naturais de ensino da leitura e da escrita implicam operações apropriadas sobre o meio ambiente das crianças. Elas devem sentir a necessidade do ler e do escrever na sua brincadeira (VIGOTSKI, 2010, p. 144).
\end{abstract}

É importante ressaltar que Vigotski faz essa relação com a brincadeira, pois para ele a brincadeira constitui a linha principal de desenvolvimento das crianças nos anos pré-escolares (VIGOTSKI, 2008). Para este autor, na brincadeira a criança vai além do que cotidianamente é capaz de realizar. Ela reproduz elementos de sua cultura e produz novos significados ao recolocar aqueles elementos, por exemplo, na inovação de um jogo simbólico. $\mathrm{Na}$ construção da linguagem, esses espaços de criação também aparecem, por exemplo, quando uma criança ao ser perguntada sobre que suco gostaria de tomar na hora do lanche, se de laranja ou de uva, responde que os dois, e cria uma nova palavra para responder ao seu desejo: "laruva" (exemplo retirado de uma situação doméstica).

Sem precisar fazer sistematizações sobre regras sintáticas ou fonológicas, a criança jog̉a com a linguagem, e nessa exploração conhece suas regras, que são as regras de uso. Há que se destacar que essa elaboração não "brota" espontaneamente no desenvolvimento da criança, mas demanda processos contínuos de interação nos quais o papel dos adultos, e especificamente dos professores na Educação Infantil, se faz de maior importância. 0 professor vai instigando, apoiando, mediando o olhar da criança para essa linguagem e ajudando-a a manejar com essa nova ferramenta simbólica que vem sendo internalizada desde que nasceu. 
Todo esse processo de letramento emergente é condição necessária para que a criança possa perceber a linguagem escrita como um "sistema particular de símbolos e signos cuja dominação prenuncia um ponto crítico em todo o desenvolvimento cultural da criança" (VIGOTSKI, 2010, p. 126).

No contexto da Educação Infantil, esse processo é marcado não só pela interação com livros ou pela interação criança-adulto, mas também pela interação com seus pares em eventos de letramento.

Ao transportar esses conceitos para a análise da interação das crianças, durante a construção de uma narrativa, o foco se direciona para as interferências das falas dos parceiros como elementos constituintes de uma mesma história, em que as sugestões do outro para o enredo precisam ser articuladas por todos no ato da construção da narrativa.

Segundo Oliveira (2011):

\footnotetext{
O processo dinâmico de coordenação de papéis que as crianças assumem, no "aqui e agora" das situações que vivenciam as leva a um contínuo negociar os sentidos que atribuem aos eventos e às posições que ocupam neste contexto, de modo a estruturar como agir para construir e alcançar seus objetivos enquanto interagem com parceiros com suas próprias e frequentemente opostas intenções (OLIVEIRA, 2011, p. 134).
}

0 "negociar os sentidos" expresso na citação intimamente se aproxima das negociações necessárias para a construção e articulação de sentidos entre as diversas vozes - por vezes contrárias ao que se esperava - em prol de um enredo coletivo. Para tanto, inúmeros e importantes recursos cognitivos e linguísticos são postos em prática e ressignificados de acordo com as interações e mediações ocorridas no instante da construção. Vejamos, então, em uma situação interativa específica, como essas elaborações foram acontecendo.

\section{Metodologia}

A pesquisa foi desenvolvida numa turma com 24 crianças na faixa etária dos 4 anos, frequentadoras de uma escola municipal localizada na zona urbana do município de Caieiras, na Grande São Paulo.

0 objetivo central da pesquisa foi o de analisar as interações das crianças em situação de construção coletiva de narrativa, bem como as sugestões/soluções encontradas por elas aos desafios 
dessa construção. Durante esse processo, o papel da professora foi o de escriba da narrativa sugerida pela turma, além de mediadora na construção do enredo.

Para apoiar o mapeamento das condições contextuais relativas às práticas de letramento na instituição pesquisada, foram utilizados alguns indicadores sugeridos por Ferreira (2013), além dos Indicadores da Qualidade na Educação Infantil (2009c), mais precisamente o indicador referente à dimensão "Multiplicidade de Experiências e Linguagens". A partir daí, foram construídos indicadores direcionados à análise da escola por meio de perguntas como: Que tipo de portadores textuais estão acessíveis às crianças? Há variedade de gêneros textuais à disposição das crianças? Em que medida, nos diversos momentos da rotina, as crianças são ouvidas? Como as crianças interagem com os portadores textuais? Como as crianças se expressam nos momentos de rodas de conversa? As crianças expressam hipóteses a respeito da linguagem (oral ou escrita)?

De uma forma geral, observaram-se na instituição condições favoráveis à construção de um ambiente rico em possibilidades de experiências com a linguagem verbal - oral e escrita ${ }^{3}$ - e gestual. Foram observados diversos portadores e gêneros textuais, assim como o acesso e manuseio destes pelas crianças em diferentes momentos. Além disso, durante o desenvolvimento da rotina, foram observadas atividades e projetos de trabalho envolvendo as diferentes modalidades da linguagem verbal.

As observações realizadas no contexto da escola de Educação Infantil aconteceram em um período de aproximadamente seis meses. Nessa investigação de campo, foram feitos registros que focaram os indicadores destacados anteriormente. Parte desses encontros foi reservada ainda para conversas com a professora e a coordenadora, a fim de compreender como eram desenvolvidas as ações voltadas às práticas de oralidade e escrita, além de planejar a proposta e a filmagem de uma situação de interação, que envolvesse práticas de leitura e escrita.

Após algumas observações das condições contextuais relativas às práticas e eventos de letramento, especialmente da turma observada, foi realizada a filmagem em vídeo de um momento de criação coletiva de uma narrativa escrita com as crianças.

No planejamento dessa atividade, a professora optou por utilizar como base um livro de imagens, intitulado Telefone sem $\mathrm{Fio}^{4}$ (2010), de Ilan Brenman e Renato Moriconi, como apoio para
3. Esse aspecto não será mais amplamente detalhado, considerando o recorte deste artigo. Mais detalhamentos em relação à análise desses indicadores constam do trabalho: PANCOTTO, André Luiz. Coisas Engraçadas: análise de interações no contexto de construção de uma narrativa em uma escola de Educação Infantil. Monografia. Instituto Superior de Educação Vera Cruz. São Paulo/SP, 2015. Disponível na biblioteca do Instituto Vera Cruz (São Paulo - SP).

4. No link a seguir, disponibilizado pela própria editora, é possível perceber um pouco a proposta do livro. http://www. companhiadasletras.com.br/ trechos/40641.pdf 
a criação do enredo. 0 livro apresenta uma personagem em cada página, simulando a brincadeira de telefone sem fio, num total de 14 personagens diferentes - algumas relacionadas ao universo das histórias infantis, como o rei, a vovó, o caçador, o lobo e a Chapeuzinho Vermelho.

A proposta se inicia com a professora contextualizando a situação para a turma, lançando o desafio da construção da narrativa, que é aceito de imediato pelas crianças. 0 vídeo de 20 minutos e 47 segundos, foi transcrito na íntegra (com alteração dos nomes das crianças), recortado em episódios (cujos tempos são indicados no presente texto), que foram analisados de acordo com os eixos de análise explicitados a seguir:

1. Articulação da oralidade e da escrita:

- Que marcas da linguagem escrita aparecem na oralidade das crianças?

- De que forma a professora articula a transposição da linguagem oral para a linguagem escrita?

- Quais recursos linguístico-discursivos a professora oferece como sugestão para articular as linguagens?

- Qual a reação das crianças diante da articulação da professora?

2. Aspectos do pensamento, fala e gestualidade das crianças:

- Como, nos episódios, pensamento e fala emergem na construção da narrativa?

- De que forma a movimentação e os gestos ou expressões faciais das crianças compõem a construção da narrativa?

3. Interferência das interações na construção da narrativa:

- De que forma as interações analisadas pareceram interferir na narrativa construída coletivamente?

A construção dos eixos de análise permitiu apurar o olhar para as interações num momento coletivo, constituído por um número elevado de vozes e expressões gestuais que se confundiam e que se articulavam em prol da construção de um produto coletivo. 


\section{Análise das interações}

Inicialmente, a questão a se destacar diz respeito ao convite feito pela professora e o envolvimento imediato das crianças. Atenta à problemática lançada pela professora, a turma, em busca de solução, se deixa envolver pelos questionamentos desafiadores dela, intensificados pela pergunta: "E como que eu vou ler a história pra vocês?"; até a sugestão de uma integrante do grupo: "Escrevendo..."!

Eis o primeiro episódio, que dispara a atividade proposta:

Episódio: "Vamos fazer assim..." (0m - 1m36s)

PROFESSORA: Turminha, agora a gente vai fazer a nossa Roda de História do dia, tá bom? Roda de História... Só que essa Roda de História de hoje tem uma questão importante... Olha só o que acontece com este livro que eu trouxe pra vocês (a professora mostra páginas do livro). O livro tem o quê?

LÍVIA: Coisas engraçadas?

PROFESSORA: Coisas engraçadas... imagens, né?

LÍVIA: Tem palhaço?

PROFESSORA: Imagens... Palhaço... Mas cadê a história?

CRIANÇA: Rei!!

PROFESSORA: Cadê a história aqui em cima? Ou aqui embaixo?

LÍVIA: Não tem nenhuma história (emite um ruído pela boca, como um estalo de dedos).

PROFESSORA: Não tem nenhuma história?

CRIANÇA: Não!

LÍVIA: É um livro sem... É um livro sem... coisas pra ler... (levanta o braço enquanto fala).

PROFESSORA: Ué! E como que eu vou ler a história pra vocês?

REBECA: Ô Prô, ô prô-ô, sabe? Aqui dentro tem pirata do "Terra à vistaaa!" (enquanto fala, gesticula bastante os braços).

PROFESSORA: É... 
LÍVIA: Escrevendo...

PROFESSORA: E como eu vou ler a história, se não tem história?

LÍVIA: Escrevendo...

PROFESSORA: Inventando?

LÍVIA: É!

PROFESSORA: E quem vai inventar a história?

LÍVIA: Você!

PROFESSORA: Eu?! Sozinha?!

MARIANA: EU!

PROFESSORA: Será que eu vou conseguir?

LÍVIA: Não, a gente ajuda, né?

PROFESSORA: Ahhh... Que legal!!! Só você que vai me ajudar ou vocês também?

CRIANÇAS: A gente também!! A gente também!! Eu... eu... eu...

PROFESSORA: Então... Legal!! Então vamos começar?

CRIANÇAS: Sim.

PROFESSORA: Vamos fazer assim: eu seguro o livro, vou mostrando as imagens... Vocês vão falando a história, vão inventando... E eu vou escrevendo aqui (aponta para a cartolina fixada na lousa, onde escreverá a história) pra gente não perder o enredo da história. Tudo bem? Vamos começar?

CRIANÇAS: Hum-hum!

O diálogo desenvolvido nesse episódio, iniciado com o convite para investigar sobre o livro e que culmina com a negociação sobre quem escreverá a história, nos possibilita inferir os conhecimentos prévios da turma: o de reconhecimento da escrita como suporte para a leitura de histórias e também a novidade de um livro "sem palavras". Aliás, essa "surpresa inicial" diante da falta de palavras escritas já é conhecida na interação com esse tipo de obra (SOLANA, 2014).

Cabe aqui um destaque no que se refere à ideia de que "não há uma história" no livro e que, por sua vez, configura 
mais um elemento de interesse para as crianças conhecerem a multiplicidade de gêneros textuais no âmbito da literatura infantil. A obra consiste em um "livro álbum sem palavras" que de acordo com Solana (2014) é um formato exigente e que demanda participação ativa do leitor, já que, aos elementos semióticos propostos pelo autor, o leitor deve "criar pontes e preencher espaços vazios em uma tarefa interativa e recursiva de construção de significados" (idem, p. 01). Então, o livro álbum traz em si uma narração constituída por meio das imagens, apresentadas de determinada maneira e não de outra. Será essa narração o ponto de partida para a "leitura" e construção de significados pelas crianças.

Nessa perspectiva, o livro álbum ganha importância na contemporaneidade por convocar seus leitores à atividade de significar imagens e enredos. Mediações de parceiros leitores mais experientes podem abrir espaço para construções criativas e interativas a partir das obras. Nesse sentido, vale a pena ressignificar a ideia de que livro álbum "não tem história", que emerge no diálogo das crianças com a professora.

Indo além da surpresa inicial e aceitando o convite da professora para escreverem juntos uma história da turma, a partir do livro, segue-se a interação. As perguntas da professora vão, aos poucos, direcionando o foco das crianças para a construção da narrativa, além de auxiliar na articulação dos conhecimentos prévios das crianças com relação às histórias e à criação de um novo produto, apresentado como o grande desafio do momento.

Sabe-se, por meio do mapeamento feito, que as Rodas de Histórias são diárias nessa instituição, havendo um revezamento entre os leitores (ora leituras realizadas pela professora - em maior grau -, ora leituras realizadas pelas próprias crianças).

Outra informação importante para a análise está na disponibilização de livros de diferentes gêneros literários e recursos de contação, como fantoches, dedoches, entre outras possibilidades de valorização desse momento, sempre acessíveis às crianças, além das discussões sobre as leituras que são promovidas pela professora.

Por meio dessas situações de contação de histórias e leitura, as crianças se apropriam de informações importantes sobre as práticas sociais que envolvem a linguagem escrita. Ao comentar sobre a leitura das histórias, entra em jogo a mediação pela oralidade, enriquecendo as discussões pautadas por perguntas do 
tipo: "O que você achou da história?"; "Qual o trecho do enredo que mais te chamou a atenção?", dentre outras possibilidades de mediação da leitura com as conversas sobre o que se leu sobretudo quando esses momentos são promovidos de forma descontraída.

A manipulação de livros de gêneros diferenciados pelas crianças acaba por potencializar os saberes que serão utilizados futuramente, nos contextos voltados à apropriação do sistema de escrita, mas que, antes disso, já puderam ser requisitados, como se observa na construção da narrativa apresentada nesta pesquisa.

Para reforçar essa análise, pode-se convocar o conceito de letramento emergente (ROJO, 2010). O resgate dos conhecimentos sobre a linguagem escrita, construídos pelas leituras de histórias, e a utilização de recursos linguísticos próprios desse gênero apontam os saberes relativos à escrita, que inicialmente se manifestam nas conversas sobre a história.

Exemplo dessa afirmação pode ser observado no episódio seguinte, disparado pelo questionamento da professora - "Como as histórias começam?" - ao perceber que o silêncio pairava na sala ao iniciar a construção da narrativa.

Episódio: "Como as histórias começam?" (1m50s - 2m50s)

PROFESSORA: Como as histórias começam?

VÍTOR: Era uma vez!!

PROFESSORA: Era uma vez (apontando para o Vítor e começando a escrever no cartaz, com canetão). E aí?

VÍTOR: Um palhaço...

LÍVIA: ...que adorava ficar fazendo coisas engraçadas...

PROFESSORA (enquanto escreve a história narrada pela turma): Era uma vez... um palhaço... Muito bem, Lívia!

LÍVIA: Que adorava fazer coisas engraçadas...

GABRIELE: A prô... (inaudível) nem um palhaço!

PROFESSORA (ditando enquanto escreve): ...que... adorava... fazer... coisas... Como é que é?

CRIANÇAS: Engraçadas!! 
PROFESSORA: Engraçadas. E aí?

VÍTOR: Aí ele encontrou um rei.

REBECA: Ele... o palhaço, disse que ele não gostou nada...

PROFESSORA (escrevendo): Aí... Ele encontrou...

CRIANÇAS: 0 rei...

PROFESSORA (escrevendo): 0 rei...

REBECA: E o palhaço... ficou assustado com o rei...

Assim, pode-se observar a utilização dos recursos linguísticos disponíveis no repertório da turma, mediada pelo questionamento da professora: "Como as histórias começam?".

Ainda que nem todas as histórias - escritas ou contadas comecem com o convencional "era uma vez...", esta marca serviu como uma espécie de trampolim para que as crianças pudessem dar o grande salto e mergulhar na narrativa construída em parceria.

Trata-se de uma marca recorrente em determinados gêneros literários destinados às crianças, como o conto de fadas, e que é utilizada pelas crianças quando se deseja iniciar uma narrativa, mesmo algumas das que se concretizam apenas pela oralidade.

Por intermédio desse "mergulho" inicial, disparado pela mediação da professora ao resgatar elementos presentes no repertório das crianças, a narrativa ganha fluidez e possibilita maior envolvimento e participação da turma, na medida em que a sugestão de um parece mediar a fala de outro e a história vai se construindo.

Nesse episódio, é interessante destacar as relações que vão sendo estabelecidas pelas crianças e que nos dão a saber sobre a natureza do pensamento infantil, que pode ser conhecido por meio da fala da Lívia, ao ver a figura do palhaço e sugerir o que conhece sobre a personagem. Essa contingência do pensamento da criança que segue buscando elementos de suas experiências cotidianas marca a atividade criadora de que Vigotski (2009) nos fala. Ao recolocar em jogo elementos conhecidos da cultura, do cotidiano, a criança os rearticula aos elementos da narrativa e cria um enredo para a proposta feita. Assim, surge na sequência da narrativa: um palhaço "que adorava fazer coisas engraçadas". Vale anunciar 
também que essa sugestão é resgatada, posteriormente, para dar o título da história da turma.

Do ponto de vista linguístico, essa construção também faz parte da "fórmula" inicial Era uma vez X que..., usada para se fazer a apresentação inicial de personagens em histórias, construção essa mais típica do discurso escrito, especialmente dos contos clássicos, e que aqui aparece como indício de construção de uma fala letrada.

Episódio: "Como assim?! - A problemática da coerência..." $(4 m 18 s-6 m 23 s)$

PROFESSORA (virando a página do livro): Tira a mãozinha, por favor! (Falando com Rebeca, que segurava a página do livro) E aí? Quem é este aqui?

(As crianças, tentando identificar a imagem de um mergulhador - escafandrista - lançam palavras inaudíveis).

PROFESSORA: Um de cada vez (tentando acalmar a turma).

MARIANA: Mergulhador!

PROFESSORA (apontando para Mariana e chamando a atenção dos colegas): Ela falou bem legal! Fala aí!

MARIANA (repete, fazendo um gesto com a mão direita): Mergulhador.

PROFESSORA (apontando para a imagem do livro): Mergulhadooor (falando pausadamente e prolongando a sílaba final). Isso aqui é um capacete de mergulhador. E aí? Ó, vamos seguir a história! (lendo o que haviam escrito, como forma de retomar o enredo, articulando o que estava escrito com as imagens e as situações sugeridas pelas crianças)... o rei chamou o cavaleiro para matar os lobos, mas em vez de aparecer o lobo aparece um mergulhador? E aí? Como que acontece essa história?

LÍVIA (diz, com uma expressão de incompreensão, num tom de voz baixo, que parece não ter sido ouvido): Como assim?

REBECA (fazendo gestos com os braços): 0 mergardor mata o lobo!!

PROFESSORA: Ah, entendi... (vira-se para escrever no cartaz) Legal!! 
JÚLIA: E que... chamar a polícia, pra matar também!

PROFESSORA (escrevendo): ... o cavaleiro para chamar o... mas quem apareceu foi o...?

CRIANÇAS: Mergulhador.

PROFESSORA (escrevendo): ... quem apareceu...

CRIANÇAS: Mergulhador...

PROFESSORA (escrevendo): ... foi o?

CRIANÇAS (acompanhando a escrita da professora): ... mergulhador...

PROFESSORA: ... mergulhador...

REBECA (sempre movimentando euforicamente os braços): Ele faz... Ele, ele, ele mata tudo, o lobo...

JÚLIA (novamente sem ser ouvida): E tem que chamar a polícia pra matar também!

PROFESSORA (virando outra página do livro): E agora? Vamos ver? Que que vai acontecer nesta história?

CRIANÇAS: Pirata!!

PROFESSORA: 0 mergulhador falou o que para o pirata?

REBECA (Fazendo outro gesto com os braços - dando um soco na própria mão): Pra matar o lobo!

JÚLIA (levantando o dedo, como das outras vezes): Não... que chamar a polícia...

PROFESSORA: Chamar a polícia para quê?

JÚLIA: Pra matar o lobo.

PROFESSORA: Ah, então agora, vamos ver se eu entendi...

LÍVIA (falando num tom de voz baixo): Pra matar o...

PROFESSORA (lendo o cartaz e articulando com as falas das crianças): ...o mergulhador chamou o pirata, pro pirata avisar a polícia?

LÍVIA: Não, pra matar... o bandido? (em tom de dúvida, enquanto olha para a professora e para a Júlia, que havia sugerido a polícia). 
PROFESSORA: E aí, gente, vamos definir!

LÍVIA: Eu... Ô prô, eu acho que já sei... 0, o pirata não tem um gancho meio forte?

PROFESSORA: Tem.

CRIANÇA: Óia, prô!

LÍVIA: Depois quando ele for mira no chão, aí sai um fogo... depois os bandido pode andar e cair no fogo e pronto... e morrer...

PROFESSORA: Com o gancho dele?

LÍVIA: É.

PROFESSORA: Tá, então vamos voltar aqui (lendo o cartaz). Mas quem apareceu foi o mergulhador, junto com o pirata, então?

Pode ser?

CRIANÇAS: Sim.

LÍVIA (com uma expressão satisfeita): Ahhh!

0 destaque para esse episódio está direcionado para a questão da coerência buscada a partir do conflito gerado ao aparecer um mergulhador em vez do lobo, como parecia ser a expectativa das crianças.

0 desafio proposto pelo próprio livro quebra a fluência da construção da narrativa por instantes, representado pela fala da Lívia: "Como assim?". O inesperado gera um desconforto nos autores do enredo, que precisaram reelaborar seus pensamentos antes de continuar com as sugestões, e esse movimento teve contribuições dos conhecimentos sobre as linguagens já adquiridos pela rotina das leituras, conversas, manuseio de livros e suportes textuais diversos.

Ainda que tenha surgido uma possível solução para a problemática, Lívia não se mostrava totalmente convencida de que seria a melhor solução, afinal, o cavaleiro surgiu para matar um lobo que não existia até o momento.

Mesmo com a sugestão de Rebeca, com o "mergulhador mata o lobo", ainda ficou uma dúvida, que começou a ser resolvida por nova possibilidade: "E tem que chamar a polícia para matar também!". Nesse caso, a interação mediada pela oralidade oferece um ponto de equilíbrio e devolve a coerência - aos olhos de 
Lívia, que responde, ainda que em tom de dúvida, à pergunta da professora, como se vê na passagem Não, pra matar... o bandido? (em tom de dúvida, enquanto olha para a professora e para a Júlia, que havia sugerido a polícia).

Nesse caso, a coerência pôde ser devolvida à narrativa, na medida em que polícia "mata" bandido, portanto, para justificar a presença da polícia no texto, precisaria ter também um bandido, e credita ao lobo essa função - ambos vilões, daí a aproximação para, na sequência, voltar a ser lobo.

Outro destaque do episódio que merece atenção é a mediação da professora, provocando a turma justamente no ponto de desequilíbrio do enredo, com o desafio de continuar a história vencendo o obstáculo surgido: PROFESSORA: ...o rei, chamou o cavaleiro para matar os lobos, mas em vez de aparecer o lobo aparece um mergulhador? E aí? Como que acontece essa história?

Talvez tenha sido essa a provocação necessária para chamar a atenção das crianças para a articulação das sugestões com uma coerência textual, fazendo um movimento de retomar o que já havia sido escrito e articular com as falas das crianças, junto com as crianças. Podem ter sido essas interrogações da professora que causaram o desconforto em Lívia e a levaram a articular suas ideias com as dos colegas e a dar sugestões para prosseguir com a narrativa.

Todo esse movimento de articulação de vozes para a construção da narrativa é parte do processo de letramento emergente, no caso, no que se refere às (re)elaborações discursivas visando à compreensão da história que se quer contar. Garantir a coerência dos fatos criados exige grande esforço, unindo todas as articulações e conectivos necessários à coesão textual, e que são aprendidos não só nas interações orais, mas também na interação com as situações diversificadas de escrita, presentes no cotidiano escolar.

Há ainda um aspecto que merece ser indicado que é a presença forte do movimento das crianças, sobretudo nesse momento em que a narrativa vai se constituindo e as negociações em torno dela vão acontecendo. Especialmente com Wallon (1975), é possível ressaltar a necessidade dessa movimentação, inclusive apoiando a elaboração da fala e do pensamento em torno da atividade. As crianças se movem no espaço, balançam os braços, fazem gestos (de apontar, de dúvida...), enfim, elas não estão paradas em um determinado lugar, sentadas, pensando, imóveis, como 
algumas concepções em torno da aprendizagem tentam reforçar. Movimento, fala e pensamento estão aqui articulados e se apoiando. A criança lança mão de todos os seus recursos para dar conta dos desafios propostos.

Esse aspecto da movimentação das crianças volta a aparecer quando a turma está se encaminhando para o final da narrativa, o que pode ser observado no episódio seguinte:

Episódio: "Na terra dos índios" (8m38s - 9m37s):

(Dando prosseguimento à construção da narrativa, a professora vira a página do livro e surge a imagem da próxima personagem a compor o enredo):

VÍTOR: Um índio!

FELIPE: É um índio...

PROFESSORA (mostrando outra página do livro): E agora?

CRIANÇAS: É um índio!!

PATRÍCIA: É um índio!

PROFESSORA: O papagaio vive onde?

(silêncio)

PROFESSORA: Onde o papagaio vive?

LÍVIA: Na terra dos índios.

PROFESSORA: Na floresta?

PEDRO: É.

PROFESSORA: Tá.

REBECA: Não, prô.

(Neste momento, as crianças começam a sair de seus lugares iniciais - em roda - e vão, aos poucos, chegando ao centro do tapete, ficando mais próximas umas das outras).

PROFESSORA (retomando a história através da leitura, que faz apontando com o dedo): Aí apareceu um papagaio, que queria ser... participar, do navio do pirata, mas...

LÍVIA: Apareceu um índio. 
PROFESSORA: 0 índio falou o quê?

(silêncio)

LUANA: Pra matar.

JONAS: Pra matar ele.

LÍVIA: Que ele tem que ficar aí, na floresta?

MARCOS: Ô prô...

PROFESSORA (apontando para Lívia): Ah! Legal! Repete!

LÍVIA: Que ele tem que ficar na floresta, porque é o lugar dele?

PROFESSORA: Isso!! (escrevendo) Mas o índio... disse... que lugar de papagaio é onde, Lívia?

LÍVIA (com uma expressão de satisfação): Na floreeesta... Porque eu já vi no zoológico... ele num monte de galho...

PROFESSORA (escrevendo): ...papagaio... é na...

PATRÍCIA (que aparentemente estava alheia à proposta desde o início, fala para Lívia): Eu já fui na floresta.

LÍVIA (para Patrícia, com uma expressão de admiração no rosto): Sério?!

Ao buscar elementos para ilustrar a análise, destaca-se a articulação entre oralidade e escrita, mediada constantemente pela professora, que questiona e fornece elementos e conectivos linguísticos importantes para a construção da narrativa, além de retomar, durante toda a proposta, a leitura - que faz apontando o dedo para o cartaz mostrando os trechos que estão sendo lidos.

A articulação entre a leitura de imagens e a construção da narrativa também pode ser observada com facilidade a cada momento em que uma nova página do livro é virada, trazendo um novo desafio aos autores.

Outro elemento de integração de interações que precisa ser destacado se direciona para a movimentação das crianças. Em vários momentos a turma se reorganiza no tapete da sala, reconfigurando constantemente a formação inicial e, consequentemente, as interações estabelecidas.

A movimentação das crianças possibilita, com as novas parcerias, outras trocas discursivas que enriquecem a narrativa, 
haja vista que as conversas surgidas em segundo plano por vezes podem acabar se destacando e sendo integradas ao texto central.

No que se refere à movimentação, pode-se destacar que dessa forma as crianças se posicionam numa perspectiva privilegiada para a leitura das imagens, o que interfere em suas contribuições para o enredo, posto que podem capturar melhor os detalhes das imagens e suscitar novas analogias e pensamentos.

Inúmeros recursos e conhecimentos linguísticos e discursivos, presentes no repertório das crianças, foram postos à prova, reorganizados, reelaborados e ampliados por intermédio das interações promovidas durante a proposta de construção de uma narrativa.

A professora constantemente lança questionamentos próprios da linguagem oral, observados em larga escala quando se está narrando um fato, por exemplo, e que são importantes para prosseguir com a construção: "E aí?".

Ao lançar perguntas do tipo: "E aí, quem apareceu?", "0 que aconteceu depois?", "O índio falou o quê?", "Chamar a polícia para quê?" etc, a professora oferece recursos para as crianças buscarem as próprias articulações entre as linguagens e participarem de forma ativa na construção da narrativa, uma vez que as perguntas pontuais da professora exercem a função de "colocar" as crianças dentro da proposta. De novo, o movimento da professora de resgatar a leitura apontando com o dedo também oferece recursos importantes para a articulação das crianças.

Nessa vertente, conforme apontado por Rojo (2010), quanto mais participação em eventos de letramento as crianças tiverem, maiores serão os recursos de que poderão dispor para a elaboração de seus discursos. No caso analisado por esta pesquisa, é possível observar que as leituras diárias parecem ter contribuído para a construção desses recursos linguísticos pela turma, haja vista que encontram saídas - com relativa facilidade - para os desafios propostos pela atividade.

0 próprio livro que utilizaram (com uma personagem diferente a cada página) se configura como um desafio, desafio este que se intensifica com a interação mediada pela fala dos colegas, quando se veem diante de sugestões diferentes das suas e a necessidade de articular as falas para a mesma narrativa.

A efetividade da linguagem oral, permeando toda a construção da história, pode ser associada ao conceito de letramento 
emergente, e de alguma maneira ao de fala letrada, na medida em que as crianças se utilizam de todos os recursos linguísticos de que dispõem para a elaboração de um novo discurso, seja para contribuírem com suas sugestões - advindas de suas experiências cotidianas e de outras histórias -, seja para estabelecerem os ajustes e articulações necessários ao conflito de vozes que se coadunam.

No que se refere aos gestos, convém destacar que estes compõem, junto com a oralidade, os significados no aqui e agora da interação das crianças e do adulto. Os gestos e as expressões faciais dos falantes se tornam os recursos disponíveis no momento para se fazerem entender, para compartilharem os significados e constituírem os sentidos na construção da narrativa.

Os trechos que seguem servem para ilustrar o pensamento da complementaridade da fala por meio dos gestos:

PROFESSORA (manipulando o livro): Este é o final, gente. Este é o último desenho.

REBECA: Ele lambeu.

(Rebeca gesticula, imitando a imagem do cachorro lambendo o palhaço).

E depois:

PROFESSORA: Um senhor... por que que este senhor apareceu na história?

VÍTOR (levantando e gesticulando o braço, um gesto próximo do movimento de "tirar uma foto"): Ele... ele queria tirar uma foto dele...

PROFESSORA: Uma foto de quem?

VÍTOR e LÍVIA: Do índio.

Com as experiências mediadas pelas interações e articulações entre as linguagens, as crianças vão, aos poucos, ampliando o repertório linguístico e expressivo, o que favorece as elaborações discursivas e, no caso dessa atividade proposta, a construção de uma narrativa coletiva, a partir da leitura de um livro de imagens. 


\section{Considerações finais}

Nesse movimento das crianças de unir as vozes dos parceiros às suas próprias e ao enredo em construção, muitos elementos discursivos e cognitivos foram postos à prova e ressignificados ou atualizados, o que ocasionou a geração de novos significados que poderão ser, futuramente, reorganizados pelas crianças ao participarem de novos contextos linguísticos.

Nas intervenções necessárias para articular a linguagem oral (falas e sugestões das crianças) com a escrita da história e o gesto, possibilitou-se a participação ativa das crianças, assim como a chance de estas trazerem para a interação seus saberes e construírem novos sentidos em uma narrativa. Essa análise permite afirmar que a mediação da professora, como parceira mais experiente que tem maior domínio da escrita e que abre espaço efetivo para escutar e validar as vozes das crianças, contribuiu com a participação e o envolvimento da turma.

Durante diferentes momentos, o incentivo desafiador da professora - sempre pautada por perguntas: "E aí?", "Quem é este aqui?", "Por que o mergulhador apareceu na história?", "E agora, o que aconteceu?" etc. - incluía as crianças na proposta, sobretudo nos momentos de silêncio ou de instabilidade. As perguntas direcionadas à turma foram capazes de (re)inserir as crianças na construção da narrativa, além de articular os pensamentos com a fala e com a escrita.

Cabe destacar também que as Rodas de Histórias realizadas diariamente, as Rodas de Conversar, o respeito pelas falas das crianças e o manuseio de livros de gêneros diversificados contribuíram para o resultado final. 0 que permite essa afirmação é a observação da participação das crianças, que, em sua maioria, não se intimidavam diante dos desafios nem se anulavam quando sugeriram cenas que não foram ouvidas em razão das inúmeras vozes concomitantes.

Se relacionarmos essa situação pontual (analisada aqui nesta pesquisa) com as observações acerca das possibilidades de recursos e eventos de letramento disponíveis na instituição, é possível ressaltar que as crianças vivenciando um ambiente rico em situações letradas podem se apropriar de recursos linguísticos, discursivos e cognitivos de forma mais ampla para encontrar soluções às dificuldades surgidas dentro de um contexto permeado por múltiplas linguagens. 
Situações que envolvem as práticas de linguagem oral (Rodas de Conversar, Rodas de Histórias, músicas, cirandas, brincadeiras e jogos - de papéis, de nomear, de construção etc.), bem como aquelas que incluem diretamente a linguagem escrita (leituras e manuseio de suportes textuais diversificados, contato com diversos gêneros textuais, brincadeiras orais com rimas, músicas, construções orais - com professor ou parceiro mais experiente como escriba - de narrativas, bilhetes, cartas, cartazes sempre com propósitos sociais definidos etc.), se mostram bem mais pertinentes ao momento da Educação Infantil do que as que tentam antecipar o processo de alfabetização de forma mais sistematizada.

Assim, reforçando a crítica feita pelo parecer que fundamenta as atuais DCNEI (Brasil, 2009b), as práticas pedagógicas com a linguagem escrita na Educação Infantil não podem:

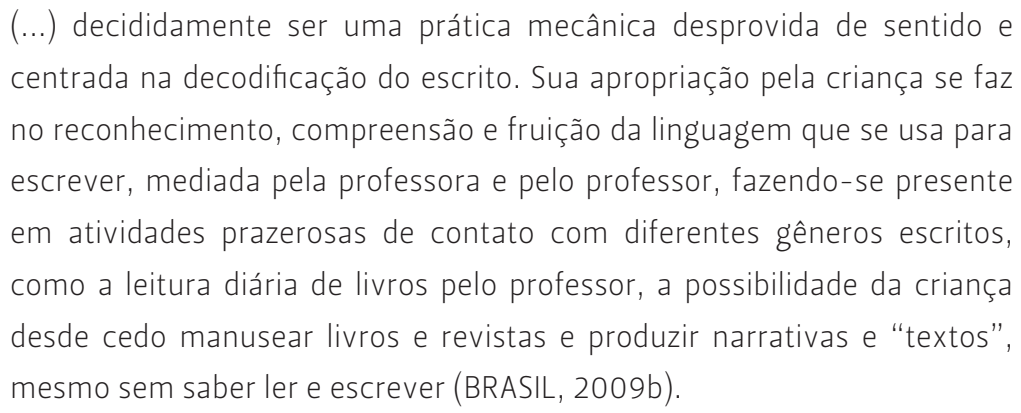

A presente pesquisa procurou, portanto, contribuir com as reflexões acerca das propostas do trabalho com as linguagens nos contextos da Educação Infantil ao apresentar a riqueza das interações das crianças, especialmente no que se refere à construção das aprendizagens em torno das linguagens oral e escrita e da gestualidade.

Além disso, cabe destacar ainda que a construção de narrativas, por todo o seu caráter simbólico, linguístico-discursivo e interacional, não só valoriza os conhecimentos já adquiridos pela criança como também oferece a oportunidade de participação ativa e de construção de novos conhecimentos no decorrer de sua produção.

Construir narrativas com as crianças, além das reflexões discutidas acima, contribui para reforçar a importância de assegurar cada vez mais o protagonismo infantil ao articular as vozes das crianças à aprendizagem das diferentes linguagens.

Enfim, no contexto da Educação Infantil, muitas são as possibilidades de proposição de atividades e projetos de trabalho que envolvem as diferentes linguagens, dentre elas a oral, a 
escrita e a gestual, possibilitando um percurso instigante e amplo de aprendizagem junto às crianças. A questão é como organizar e mediar essas propostas pedagógicas de forma contextualizada às práticas sociais de linguagem e articulada aos saberes e experiências das crianças. Assim, é possível promover mais e mais a experiência de imersão das crianças na cultura, considerando as especificidades próprias dos anos iniciais da vida e as suas possibilidades de participação e de criação.

\section{REFERÊNCIAS}

BRASIL. Ministério da Educação. Conselho Nacional de Educação. Câmara de Educação Básica. Parecer n²0, de 11 de Novembro de 2009. Revisão das Diretrizes Curriculares Nacionais para a Educação Infantil. Brasília: CNE, 2009a.

BRASIL. Ministério da Educação Conselho Nacional de Educação. Câmara de Educação Básica. Resolução $n^{\circ} 5$, de 17 de Dezembro de 2009. Fixa as Diretrizes Curriculares Nacionais para a Educação Infantil. Brasília: CNE, 2009b. . Indicadores da Qualidade na Educação Infantil. Brasília: MEC/SEB, 2009c.

BAPTISTA, Mônica Correia. A linguagem escrita e o direito à educação na primeira infância. Anais do I Seminário Nacional: Currículo em movimento - perspectivas atuais. Belo horizonte, 2010. Disponível em http://portal.mec.gov. br/docman/dezembro-2010-pdf/7159-2-7-linguagemescrita-direito-educacao-monica-correia/file (acessado em: 21.10.2017).

BRENMAN, Ilan; MORICONI, Renato. Telefone sem Fio. São Paulo: Companhia das Letrinhas, 2010.

FERREIRA, Marisa Vasconcelos. Avaliação: instrumento do professor para aprimorar o trabalho na Educação Infantil. In: Novas Diretrizes para a Educação Infantil. 2013. Disponível em: http://tvescola. mec.gov.br/tve/salto/n;jsessionid=9844 213C638AC9CF939931B5E6E1F9B4? idEdition= 8227 (acessado em 02.11.2015). 
LUIZE, Andréa. A linguagem escrita na Educação Infantil: uma análise sobre as práticas de leitura. Revista Veras, São Paulo, v.6, n.1, p. 21-32, jan./jun., 2016. Disponível em http://site.veracruz.edu.br/instituto/revistaveras/index. $\mathrm{php/revistaveras/article/view/254/159} \mathrm{(acessado} \mathrm{em}$ 22/09/2017).

MARCUSCHI, Luiz Antônio. Letramento e oralidade no contexto das práticas sociais e eventos comunicativos. In: SIGNORINI, I. (Org.) Investigando a relação oral/escrita e as teorias do letramento. Campinas/SP: Mercado de Letras, 2001.

OLIVEIRA, Zilma Moraes Ramos de. Jogo de papéis: um olhar para as brincadeiras infantis. São Paulo: Cortez, 2011.

PANCOTTO, André Luiz. Coisas engraçadas: análise de interações no contexto de construção de uma narrativa em uma escola de Educação Infantil. Monografia (Especialização). Instituto Superior de Educação Vera Cruz. São Paulo/SP, 2015.

ROJO, Roxane Helena Rodrigues. Falando ao pé da letra: a constituição da narrativa e do letramento. São Paulo: Parábola Editorial, 2010.

SOLANA, Evelyn Arizpe. Imagens que convidam a pensar: o "livro álbum sem palavras" e a resposta leitora. Revista Emília: 2014. Disponível em: http://www.revistaemilia.com. br/mostra.php?id=380 (acessado em: 23.10.2015).

VIGOTSKI, Lev. S. A brincadeira e o seu papel no desenvolvimento psíquico da criança. Tradução de Zoia Prestes. Revista Virtual de Gestão de Iniciativas Sociais. ISSN: 1808-6535. Junho 2008. Disponível em: http:// xa.yimg.com/kq/groups/32960205/729519164/name/ artigo+ZOIA+PRESTES.cg--.pdf (acessado em: 23.09.2017). - Imaginação e criação na infância: ensaio psicológico: livro para professores. São Paulo: Ática, 2009. 
A formação social da mente. 7. Ed. São Paulo:

Martins Fontes, 2010.

WALLON, Henri. Psicologia e educação da infância. Lisboa: Editorial Estampa, 1975.

Recebido: 02/10/2017

Revisto: 19/10/2017

Aceito: 06/11/2017 